\title{
Hansen solubility parameters for a carbon fiber/epoxy composite
}

\author{
Launay, Héléne; Hansen, C.M.; Almdal, Kristoffer
}

Published in:

Interface design of polymer matrix composites - mechanics, chemistry, modelling and manufacturing. Proceedings

Publication date:

2007

Document Version

Publisher's PDF, also known as Version of record

Link back to DTU Orbit

Citation (APA):

Launay, H., Hansen, C. M., \& Almdal, K. (2007). Hansen solubility parameters for a carbon fiber/epoxy composite. In B. F. Sørensen, L. P. Mikkelsen, H. Lilholt, S. Goutianos, \& F. S. Abdul-Mahdi (Eds.), Interface design of polymer matrix composites - mechanics, chemistry, modelling and manufacturing. Proceedings (pp. 221-226). Risø National Laboratory. Proceedings of the Risø International Symposium on Materials Science No. 28

\section{General rights}

Copyright and moral rights for the publications made accessible in the public portal are retained by the authors and/or other copyright owners and it is a condition of accessing publications that users recognise and abide by the legal requirements associated with these rights.

- Users may download and print one copy of any publication from the public portal for the purpose of private study or research.

- You may not further distribute the material or use it for any profit-making activity or commercial gain

- You may freely distribute the URL identifying the publication in the public portal 
Proceedings of the 28th Risø International Symposium on Materials Science:

Interface Design of Polymer Matrix Composites - Mechanics, Chemistry, Modelling and Manufacturing Editors: B. F. Sørensen, L. P. Mikkelsen, H. Lilholt, S. Goutianos, F. S. Abdul-Mahdi

Risø National Laboratory, Roskilde, Denmark

\author{
HANSEN SOLUBILITY PARAMETERS FOR A CARBON \\ FIBER/EPOXY COMPOSITE \\ Hélène Launay ${ }^{*}$, Charles Medom Hansen ${ }^{* *}$, Kristoffer Almdal ${ }^{*}$ \\ *Danish Polymer Centre, Risø National Laboratory - Technical \\ University of Denmark, Frederiksborgvej 399, P.O. Box 49, 4000 \\ Roskilde, Denmark. \\ ** Consultant, Jens Bornøs Vej 16, 2970 Hørsholm, Denmark.
}

\begin{abstract}
The focus of this work is the evaluation of the physical compatibility between an epoxy resin used as a matrix and an oxidized, unsized carbon fiber, and between this same epoxy resin and glassy carbon. For this purpose, carbon fibers, glassy carbon and epoxy resin have been assigned Hansen solubility (cohesion) parameters (HSP) by analysis of their interactions with a set of well-defined liquids. A strong physical affinity between the epoxy matrix and the carbon fibers has been shown, since their respective HSP are close. The use of a glassy carbon substrate as a model for unsized carbon fiber has been demonstrated as appropriate for the study of interactions between the materials in composite carbon fiber-epoxy systems, since the HSP of glassy carbon are similar to the ones of the studied carbon fibers.
\end{abstract}

\title{
1. INTRODUCTION
}

Fiber-reinforced composites are used in a wide range of applications where high stiffness and strength-to-weight ratios are required. The mechanical performance of composite materials depends not only on the matrix and the reinforcing fiber properties, but also to a great extent on the fiber/matrix adhesion. The physical compatibility between the fibers and the matrix can have a profound effect on the interface properties.

The experimental investigation of the fiber/matrix adhesion often involves the use of glassy carbon as a planar model surface for carbon fibers. Glassy carbon is an amorphous-like, dense material consisting of disordered phases of $\mathrm{sp}^{2}$-hybridized carbon atoms randomly interspersed with regions of amorphous carbon (McCulloch, Prawer, Hoffman 1994). Due to its structural similarities with carbon fiber (Jenkins, Kawamura 1976), extremely high hardness and modulus, chemical inertness, high temperature resistance, electrical conductivity, low cost and availability, glassy carbon is often considered as an ideal model for carbon fiber. Glassy carbon plates are moreover easier to handle and to surface characterize, thus allowing straightforward 
analysis of the mechanical tests.

Hansen solubility (cohesion) parameters (HSP) are widely used for predicting compatibility between two materials (Hansen 1999). The concept described by Hansen is based on the fact that the cohesive energy of a liquid, which can be directly measured by its energy of vaporization, arises from the contribution of three kinds of interactions: (i) nonpolar, atomic (dispersion) interactions (D), (ii) molecular, dipolar interactions (P) and (iii) molecular, hydrogen bonding interactions $(\mathrm{H})$ (Hansen 1999). These three major types of interaction are quantitatively described by the three Hansen parameters $\delta_{\mathrm{D}}, \delta_{\mathrm{P}}$, and $\delta_{\mathrm{H}}$, respectively. Materials with similar HSP will show physical affinities.

The experimental method for the determination of HSP is based on the observation of the interaction or absence of interaction between the studied material and well-known solvents (Hansen 1999). This difference of interaction is used to divide the solvents into two groups, one which is considered "good" and the other which is considered "bad". "Good" solvents interacting strongly with the material have HSP closer to those of the material than "bad" solvents giving little interaction, and are used to assign HSP to the studied material.

In this study Hansen solubility (cohesion) parameters of an epoxy resin, oxidized, unsized carbon fibers and glassy carbon have been calculated by analysis of their interactions with a set of well-defined liquids. The degree of swelling is the type of interaction chosen for the characterization of the cross-linked epoxy resin studied here. Cohesion parameters of carbon fibers and glassy carbon, in powder form, were evaluated by observing the sedimentation behavior of the particles in different solvents (Hansen 1999). Particles with a strong affinity for a solvent give a lowered sedimentation rate and the solvent is then considered as "good". On the other hand a relatively faster sedimentation in a given solvent happens in case of low affinity, and the solvent is considered as "bad". The physical affinity between the fibers and the matrix is estimated, and a comparison of carbon fibers and glassy carbon HSP allows a discussion on the relevancy of using glassy carbon as a model for carbon fiber for the study of adhesive properties of carbon fibers.

\section{EXPERIMENTAL}

2.1. Materials. The epoxy resin (bisphenol F-epichlorhydrin epoxy/bisphenol A-diglycidylether) and the hardener (polyoxyalkyleneamine/3-aminomethyl-3,5,5-trimethylcyclohexylamine) were mixed at a ratio of $10 / 3$ by weight at room temperature. The curing time was 48 hours at room temperature.

Planar glassy carbon (SIGRADUR G) was purchased from HTW Hochtemperatur. XPS analysis of the glassy carbon plate surface showed that the surface was slightly oxidized (about $5 \% \mathrm{O}$ ). Oxidized, unsized carbon fibers (TENAX J HTA-5001) were obtained from TOHO TENAXCO LTD.

Analytical grade test solvents with a wide range of known solubility parameters (Hansen 1999) were selected and used as received.

2.2. Measurements. The cured epoxy was cut into thin pieces of $25 \mathrm{mg}$. Each piece was placed into a standard test tube containing a test solvent $(7.5 \mathrm{~mL})$. The tube was sealed with a cap and allowed to stand at room temperature for two days. The behaviour of the epoxy sample was observed visually. Solvents in which a swelling of the resin was observed after two days of exposure were considered as being good. Solvents were labeled as bad in case of no interaction 
at all between solvents and resin.

Glassy carbon plates were milled and sieved to obtain fine particles having diameters below 10 $\mu \mathrm{m}$. A larger particle size should be avoided to enhance surface effects (Hansen 1999). Glassy carbon particles $(0.5 \mathrm{mg})$ were placed into a standard test tube containing a test solvent $(7.5$ $\mathrm{mL}$ ). The concentration of particles was $0.067 \mathrm{mg} / \mathrm{mL}$. The tube was sealed with a cap and sonicated for $60 \mathrm{~min}$. After sonication, the tube was allowed to stand. The dispersion stability was observed visually. Solvents in which particles were completely deposited on the tube bottom after 60 min sonication were considered as bad. Solvents were good when complete sedimentation required more than one hour after the sonication step.

For carbon fibers, a visual observation of the speed of sedimentation was not sufficient to discriminate between good and bad solvents unlike for glassy carbon. A relative sedimentation time (RST) was calculated using equation (1). This allowed a normalization of the observed sedimentation time $t_{s}(\mathrm{~min})$ with the solvent viscosity, $\eta$ (Pa.s), and density difference between particles and solvent, $\left(\rho_{\mathrm{p}}-\rho_{\mathrm{s}}\right)\left(\mathrm{g} \cdot \mathrm{mL}^{-1}\right)$. Good and bad solvents were identified by choosing a cut-off value for RST.

$$
R S T=t_{s}\left(\rho_{p}-\rho_{s}\right) / \eta
$$

Carbon fibers were cut to $3 \mathrm{~mm}$ length. Fiber length and concentration were optimized in a previous study, where the best conditions were $3 \mathrm{~mm}$ length with a fiber concentration of 0.033 $\mathrm{mg} / \mathrm{mL}$. These conditions allowed a sufficient visualization which did not require the help of a small laser. Another study on carbon nanotubes used a concentration of $0.067 \mathrm{mg} / \mathrm{mL}$, which was diluted enough to prevent aggregation (Ham, Choi, Chung 2005). The same concentration of $0.067 \mathrm{mg} / \mathrm{mL}$ was chosen for studying the carbon fibers in the test solvents. The test tube with the fibers was shaken well and sedimentation time was measured. The sedimentation time measurements started when the test tube was allowed to stand and stopped with the complete sedimentation of the fibers.

Once good and bad solvents are identified, these data are processed by a computer program developed by Hansen (Hansen 1999) to obtain the three HSP and the radius value, Ro, of the sphere of interaction for the materials studied. Ro gives the maximum difference in affinity allowed for a "good" interaction between solvent and material. The level of interaction allowing the distinction between good and bad solvents is chosen arbitrarily, like for example the cut-off value for RST. Several attempts might be necessary for a good correlation (a correlation coefficient close to one).

\section{RESULTS}

The HSP for epoxy resin and glassy carbon were, by coincidence, identical with an excellent correlation coefficient of 1.0 (Table 1). The high data fit may be partly due to the low number of tested solvents. This helped to allow a perfect separation of the good and bad solvents by the HSP correlation. Fig. 1 shows a 3-dimensional plot of the HSP found with the glassy carbon correlation. The sphere, whose center is the HSP for glassy carbon and radius is Ro (Table 1), encompasses the region of the higher surface affinities of glassy carbon. The tested solvents are marked with dots. All the good solvents are inside the HSP sphere and all the bad ones are outside. 2-dimensional projections on the $\delta_{\mathrm{D}}$ versus $\delta_{\mathrm{H}}$, and $\delta_{\mathrm{H}}$ versus $\delta_{\mathrm{P}}$ planes on Fig. 1 are shown to help for better visualization of the situation. 
Table 1: HSP, radius of interaction Ro and correlation coefficients (data fit) of epoxy resin, glassy carbon and carbon fibers correlations.

\begin{tabular}{ccccccc}
\hline Material & $\boldsymbol{\delta}_{\mathbf{D}}\left(\mathbf{M P a}^{1 / 1}\right)$ & $\boldsymbol{\delta}_{\mathbf{P}}\left(\mathbf{M P a}^{1 / 2}\right)$ & $\boldsymbol{\delta}_{\mathbf{H}}\left(\mathbf{M P a}^{1 / 2}\right)$ & $\mathbf{R o}\left(\mathbf{M P a}^{1 / 2}\right)$ & Data fit & No. $^{*}$ \\
\hline Epoxy resin & 20.0 & 10.0 & 8.0 & 9.0 & 1.000 & $7 / 18$ \\
Glassy carbon & 20.0 & 10.0 & 8.0 & 9.0 & 1.000 & $6 / 13$ \\
Carbon fibers & 21.3 & 8.7 & 11.5 & 9.3 & 0.861 & $8 / 36$ \\
\hline
\end{tabular}

*No.: number of good solvents interacting with the studied material over the total number of solvents.

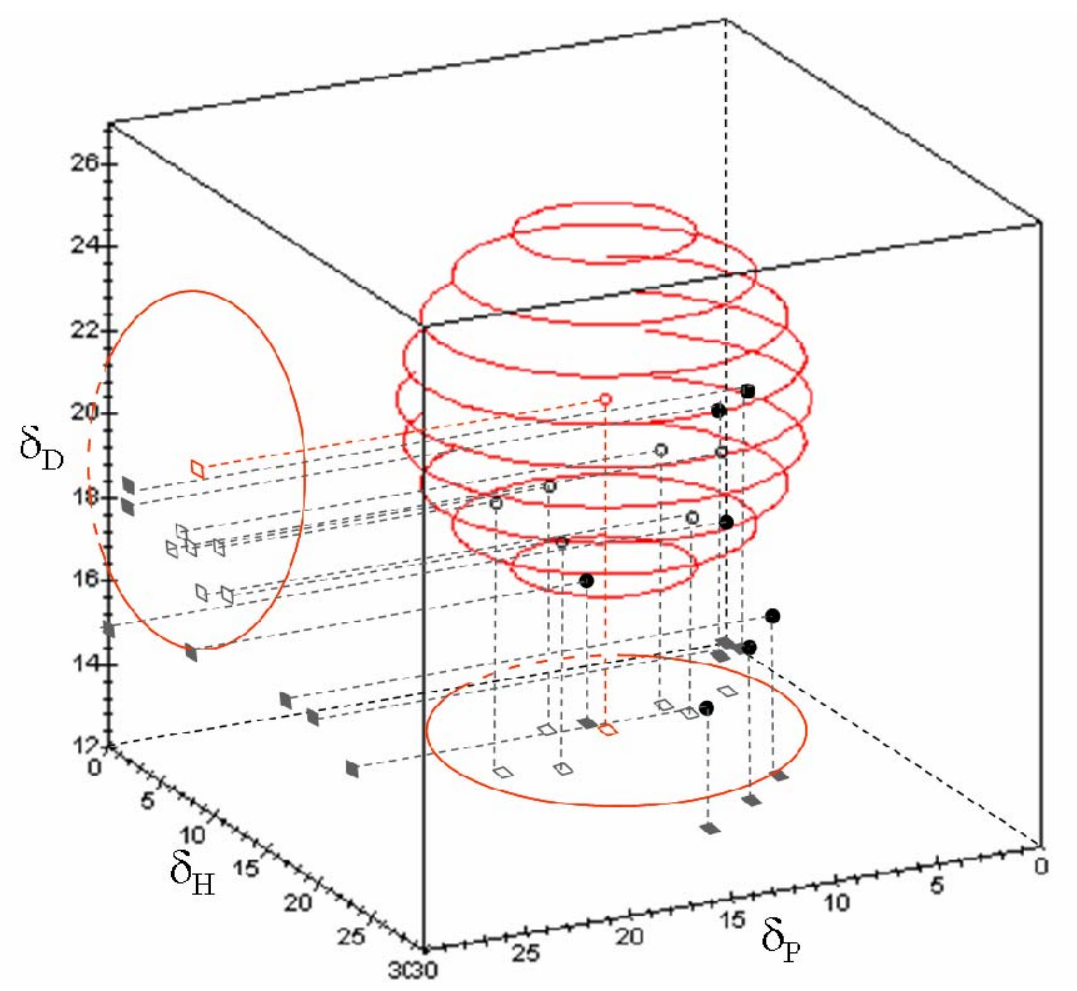

Fig. 1. 3- dimensional plot and projections of the glassy carbon sphere of surface affinity and of the tested solvents used for the correlation ( $\circ$ : inside the sphere, $\bullet$ : outside the sphere).

HSP for carbon fibers were evaluated using 36 test solvents (Table 1). The more solvents tested, the better the sphere boundary is defined. This is important for a good correlation since it is the boundary which is used to define the center point of the sphere (Hansen, 2007). A preliminary study with 18 test solvents gave a sphere of interaction with a large radius $\left(16.5 \mathrm{MPa}^{1 / 2}\right)$ and several outlier solvents which were not considered in the correlation. Additional solvents with HSP in the boundary region were then selectively chosen and tested until the lowest radius Ro was reached with the maximum correlation coefficient (Table 1). A cut-off RST of 5.9.10 min.g. $\mathrm{mL}^{-1} \cdot \mathrm{Pa}^{-1} \cdot \mathrm{s}^{-1}$ was chosen to separate good solvents from bad solvents, allowing a reasonably good correlation. The correlation coefficient was 0.861 .

\section{DISCUSSION}

Table 1 shows that epoxy resin and glassy carbon have the same HSP and radius of interaction. Their regions of affinity/solubility are exactly superposed when the criteria of "good" and "bad" 
were chosen as reported in the above. This indicates a very high physical attraction between them. In our study, epoxy resin was cured at room temperature. Specimen preparation for mechanical studies usually uses a curing procedure at high temperature for a faster process. At higher curing temperatures, no change of the center of the sphere of solubility should be expected, but the sphere radius might decrease, as observed by Storm, Gwisdalski, Lindvang and Rann (2005). A higher curing temperature leads to smaller radius value because of increased cross-linking and thus greater resistance to solvent uptake.

Mechanical tests for the glassy carbon-resin interface characterization involve the use of planar substrates. However the present investigation of the glassy carbon HSP was done on particles. The same kind of study could indeed have been carried out on glassy carbon plates comparing contact angles of the test solvents. But this method is less precise than sedimentation tests as only liquids with a higher surface tension than the surface allow measurement of a contact angle (Hansen 2007). Moreover glassy carbon particles were directly obtained from plates by grinding, thus ensuring the same surface properties to the extent that this is possible.

The sphere A in Fig. 2 represents the region of interaction of both epoxy resin and glassy carbon, these two materials having the same parameters. Comparing with the sphere of surface affinity of carbon fibers (sphere B, Fig. 2), it can be clearly seen that the two spheres are almost superposed. The carbon fibers of this study should have good physical affinities for epoxy materials, since their HSP regions of affinity/solubility are very similar. Moreover carbon fibers and glassy carbon have very close HSP regions. Their physical affinities towards another material should then be comparable. It appears that it is justifiable and relevant to use glassy carbon as a model for carbon fiber for the studies of interactions between the materials in composite carbon fiber-epoxy systems.

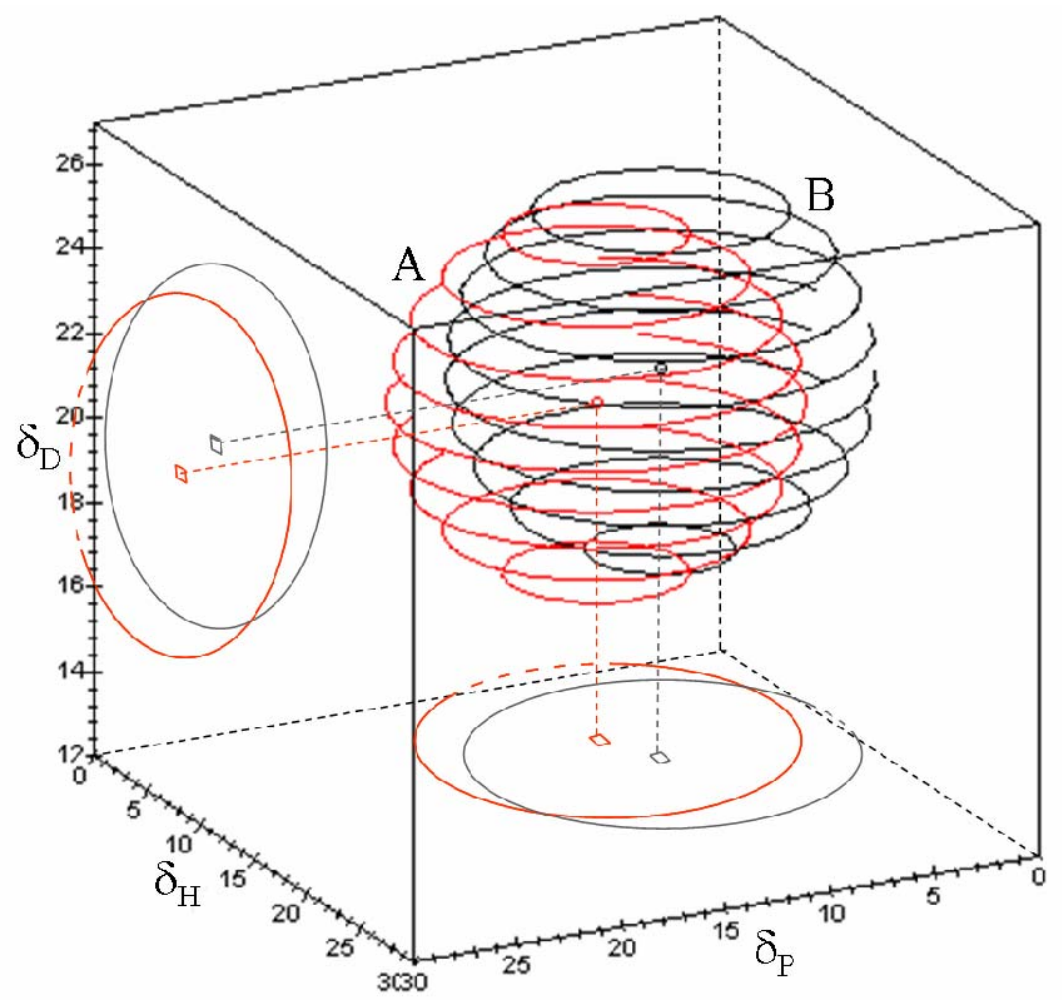

Fig. 2. 3- dimensional plot and projections of the cured epoxy/glassy carbon (A) and carbon fiber (B) spheres of interaction. 


\section{CONCLUSIONS}

Hansen solubility parameters have been assigned to a cured epoxy resin, unsized and oxidized carbon fibers, and glassy carbon.

This study has shown that glassy carbon and unsized, oxidized carbon fibers have close HSP. Both materials have comparable and excellent physical affinities towards the epoxy matrix that was also studied. Glassy carbon appears then to be a good model for the carbon fibers studied here.

This investigation has focused on physical affinities only, at the interface between the carbon materials and the epoxy polymer. Chemical treatments which could provide covalent bonding between fibers and matrix, are clearly possible, but have not been considered here.

\section{ACKNOWLEDGEMENTS}

This work was done as a part of the Framework Program "Interface Design of Composite Materials" with the support of the Danish Technical Research Council (STVF fund no. 26-030160).

\section{REFERENCES}

Ham, H.T., Choi, Y.S., Chung, I.J (2005). An explanation of dispersion states of single-walled carbon nanotubes in solvents and aqueous surfactant solutions using solubility parameters. Journal of Colloid and Interface Science 286, 216-223.

Hansen, C.M. (1999). Hansen Solubility Parameters - A User's Handbook. Boca Raton, FL: CRC Press.

Hansen, C.M. (2004). Aspects of solubility, surfaces and diffusion in polymers. Progress in Organic Coatings 51, 55-66.

Hansen, C.M. (2007). Surface characterization using Hansen Solubility (Cohesion) Parameters. 28th Risø International Symposium on Materials Science: "Interface design of polymer matrix composites - mechanics, chemistry, modelling and manufacturing".

Jenkins, G.M., Kawamura, K. (1976). Polymeric Carbons. Cambridge University Press, Cambridge.

McCulloch, D.G., Prawer, S., Hoffman, A. (1994). Structural investigation of xenon-ion-beamirradiated glassy carbon. Physical Review B 므, 5905-5917.

Storm, B.K., Gwisdalski, M., Lindvang, D., Rann, M. (2005). Investigation of degradation of structural adhesives under influence of chemicals. Macromolecular Symposia 225, 205-219. 